\title{
Sistema de Alerta Para Possíveis Cheias Utilizando Voip e Telefonia Convencional, Para Defesa Civil do Município de Caucaia-Ce, Brasil
}

\author{
José Ronildo Reis Franceschini ${ }^{1}$, Vicente de Paula Silva Filho ${ }^{2}$, Vanessa de Almeida Dantas ${ }^{2}$ \\ ${ }^{1}$ Centro Universitário Estácio do Ceará, Fortaleza, CE, Brasil. \\ ${ }^{2}$ Instituto Nacional de Pesquisas Espaciais, Eusébio, CE, Brasil.
}

Recebido em: 17 de Abril de 2020 - Aceito em: 7 de Julho de 2020

\begin{abstract}
Resumo
O presente trabalho apresenta o desenvolvimento de um sistema de alerta de possíveis inundações, para a Defesa Civil do município de Caucaia-Ce, Brasil, na Região Metropolitana da cidade de Fortaleza - Ce (RMF). O sistema possibilita informar automaticamente, a estimativa da ocorrência de possíveis inundações em áreas de risco. Centros urbanos, como a região estudada, sofrem com o aumento do risco de acidentes por meio de ocupações em áreas ao longo das margens de rios, lagoas e encostas, proporcionando o registro de desastres ambientais envolvendo perdas humanas e materiais relacionados à desinformação sobre vulnerabilidades e seus riscos. A metodologia foi desenvolvida a partir de pesquisa quantitativa aplicada, com registros bibliográficos, documentais e dados meteorológicos. Baseado no software Linux Ubuntu, o sistema utiliza a tecnologia Voice over IP (Protocolo de Voz sobre Internet), que permite o envio automático de SMS, e-mails e telefonemas, que permitem antecipar ações de mitigação pelos setores competentes e informar a população para que possam salvaguardar seus bens e vidas. Além disto, contribui para o dimensionamento das ações a serem tomadas. Essa pesquisa conclui que a junção dessas informações e divulgação prévia, junto a defesa civil, pode imprimir valor à criação de uma futura cultura de prevenção de enchentes.
\end{abstract}

Palavras-chave: Defesa Civil, monitoramento de cheias, telefonia voz sobre IP.

\section{Alert System for Possible Floods Using Voip and Conventional Telephony, for Civil Defense in the Municipality of Caucaia-Ce, Brazil}

\begin{abstract}
This work presents an alert system for possible floods, for the Civil Defense of Caucaia-Ce, Brazil (Metropolitan Region of the city of Fortaleza - RMF). The system makes it possible to automatically inform the estimate of the occurrence of possible floods in areas at risk. Urban centers, such as the region studied, suffer from the increased risk of accidents through occupations in areas along river banks, lagoons and slopes. This provides records of environmental disasters involving human and material losses, related to misinformation about vulnerabilities and their risks. The methodology was developed from applied quantitative research, with bibliographic, documentary records and meteorological data. Based on Linux, the system uses Voice over IP (Voice over Internet Protocol) technology, which allows the automatic sending of SMS, emails and phone calls, which allow anticipating mitigation actions by the competent sectors and informing the population so that they can safeguard their property and lives. In addition, it contributes to the dimensioning of the actions to be taken. The combination of this information and previous disclosure, together with the civil defense, can add value to the creation of a future flood prevention culture.
\end{abstract}

Keywords: Civil Defense, flood monitoring, voice over IP telephony.

\section{Introdução}

Com um sistema dinâmico, o nosso planeta está em constante modificação pela ocorrência dos fenômenos na- turais. Parte destes fenômenos tem origem na dinâmica interna da Terra, como a movimentação de placas tectônicas que geram atividades vulcânicas, terremotos e tsunamis. Outros são de origem externa como as atividades

Autor de correspondência: Jose Ronildo Reis Franceschini, josefraces45@gmail.com. 
solares e tem como causa principal a dinâmica atmosférica, que pode causar furacões, tempestades, ressacas, vendavais, secas, inundações, estiagem, entre outros. As intervenções humanas, como a exploração dos recursos naturais, o uso e a ocupação dos espaços naturais, também geram impactos. Parte deles pode ser absorvida, ou seja, os impactos ocorrem sem esgotar os recursos naturais; entretanto, outros são tão intensos que acabam desencadeando um desequilíbrio ambiental, e a resposta da natureza a essas intervenções tende a atingir um novo equilíbrio que se manifesta por meio de fenômenos naturais de origem externa. Entre os principais fenômenos naturais que podem ser induzidos ou potencializados pelo ser humano estão às cheias, inundações, enchentes, erosão, deslizamentos de solo, erosão marinha, que contribuem para a ocorrência de eventos desastrosos (Amaral e Gutjahr (2011).

Estes eventos variam em tempo e espaço, conforme as vulnerabilidades existentes ou criadas por ações antrópicas indevidas, como o processo de urbanização, uso inadequado de recursos hídricos, entre outros. Ao longo das últimas três décadas, estas vulnerabilidades tem sido campo de estudo para especialistas. A variação espacial destas ocorrências é um aspecto fundamental dos riscos naturais e de fenômenos extremos, que têm sido um tema fecundo para seus estudos (Alexander, 2004). Castro e Calheiros (2007) definem que "Os desastres naturais ocorrem quando provocados por fenômenos e desequilíbrios da natureza. Nesses casos, são provocados por fatores de origem externa, que atuam independentemente das ações humanas". Já Tominaga e Amaral (2009), afirmam "Quando os fenômenos naturais atingem áreas ou regiões habitadas pelo homem causando-lhe danos, passam a se chamar desastres naturais".

A ocorrência e a intensidade dos desastres naturais dependem mais do grau de vulnerabilidade das comunidades afetadas do que da magnitude de eventos adversos. Os eventos extremos ocorridos nos últimos cinco anos no Brasil geraram recordes de impactos sobre a população, desabrigando milhares, levando a óbito centenas, e mobilizando diversos segmentos sociais, acadêmicos e dos governos. O número e a intensidade dos desastres, provocados especialmente por inundações e deslizamentos, são crescentes, ocasionando impactantes perdas de vidas humanas e bens (UFSC, 2013).

$\mathrm{O}$ homem vem intensificando alterações no meio ambiente a fim de moldar o meio físico às suas necessidades e usos. Tais alterações provocam perturbações no equilíbrio dos sistemas naturais que, em função das características intrínsecas do território e da interação e magnitude dos eventos agravados pelas mudanças climáticas, resultam em situações de vulnerabilidade que podem provocar desastres (Relatório Anual Banco Mundial, 2012).

As vulnerabilidades ambientais sugiram com as primeiras aglomerações humanas. Este fato é potencializado com o forte crescimento das cidades, aliado à falta de um ordenamento territorial. Ocupações indevidas ocorrem em áreas com vertentes inclinadas, solos instáveis, planícies de inundação, entre outros, ambientes impróprios para uso residencial. As razões para o surgimento de vulnerabilidades muitas vezes são atribuídas a alterações do ambiente e a ações antrópicas, sem que o agente causador se considere como parte envolvida no processo. Estas condições determinam a ocorrência de desastres naturais (Marandola Jr. e Hogan, 2004).

Os registros de desastres nas últimas décadas mostram que muito do que vem ocorrendo no Brasil, e no Ceará particularmente, está intimamente ligado à desinformação sobre as vulnerabilidades e riscos existentes em determinas áreas urbanas. De acordo com o IBGE, 185.749 cearenses vivem em áreas de risco. Esse número corresponde a $2,2 \%$ da população do Estado. No Ceará existem 316 áreas de risco identificadas pela pesquisa "População em áreas de risco no Brasil". De acordo com aquele levantamento, 1.327 domicílios cearenses estão erguidos em áreas suscetíveis a desastres naturais como inundações, enxurradas, deslizamentos e desabamentos, fazendo do Ceará o nono estado brasileiro com maior número de moradores nesta situação. Já na região nordeste, $o$ território cearense fica em terceiro, mas bem distante dos dois primeiros colocados: Bahia com 1.375 .788 e Pernambuco com 829.058 (IBGE, 2010).

No Ceará, 39 cidades são monitoradas pela defesa civil do estado, dentre as quais Fortaleza lidera concentrando $55,3 \%$ das pessoas que vivem em em situação de risco no estado. São 102.836 moradores distribuídos em 89 áreas, o que corresponde a 4,2\% dos habitantes do município. Com o resultado, a Capital é a $12^{\circ}$ cidade brasileira com maior população em domicílios vulneráveis. Atrás da capital cearense, Caucaia, na Região Metropolitana, aparece na pesquisa com 16.463 pessoas expostas em 4.436 domicílios, que corresponde a $26,96 \%$ de sua população; seguida por Sobral, no Norte do estado, onde 10.494 pessoas vivem em 2.716 moradias de risco.

A maioria dos rios de Caucaia caracteriza-se por serem temporários, como por exemplo, o Rio Gavião, também conhecido como Riacho Picuí. O Plano de Contingência realizado em 2010 pela Prefeitura Municipal de Caucaia revelou que no bairro Picuí, onde passa o rio de mesmo nome, 1.400 famílias vivem em condição de risco às suas margens. No período de chuva, estas são atingidas por cheias e alagamentos que causam danos diversos em suas residências, e doenças provenientes das baixas condições sanitárias do local. Na região de Caucaia como um todo, muitas famílias perdem bens materiais, e às vezes ocorrem até acidentes fatais em decorrências desses fatos.

Para contribuir no monitoramento dos desastres oriundos de cheias que afetam o município de Caucaia, criouse um sistema automático de informações padronizadas de mensagens para sua Defesa Civil, utilizando a tecnologia 
Voz sobre IP, baseado no sistema operacional Linux Asterisk (O Asterisk é um software, baseado em licença publica que executa todas as funções de uma central telefônica convencional). Este sistema foi denominado de Slapvoip (Sistema Automático de possíveis cheias sobre Voip). Não foi encontrado no desenvolvimento do trabalho nem um sistema automático similar, pois esse é simples de programar usando uma linguagem de programação aberta, de baixo custo operacional. Utiliza o conceito de computação em nuvem e é construído sem a aquisição de hardwares sofisticados. É um sistema fácil de operar em comparação, com outros que são compostos por tecnologias algumas vezes mais dispendiosas, e apresentam a necessidade de pessoal qualificado para sua operação. Em relação a sua instalação, pode-se usar um celular simples, com ou sem o sistema Android, visto que as chamadas e envios de SMS são feitas mesmo sem o funcionamento da Internet através da Rede Convencional de Telefonia Pública- PSTN.

\section{Material e Métodos}

O município de Caucaia integra a Região Metropolitana de Fortaleza (RMF). Compreendendo uma área de $1.227,9 \mathrm{~km}^{2}$, equivale a $0,83 \%$ da superfície estadual, e abrange um contingente populacional de 325.441 habitantes (IBGE, 2010), Fig. 1.

Em relação aos aspectos ambientais, a estrutura geológica do município foi estudada por Souza (1988), Souza et al. (1995), sendo que a mesma apresenta dois conjuntos bem distintos: Coberturas sedimentares de idade TércioQuaternária e litologias do embasamento cristalino précambriano. O relevo da cidade de Caucaia é m999arcado por altitudes médias a baixas geralmente inferiores a $1.000 \mathrm{~m}$, sendo composto pelos tabuleiros pré-litorâneos, depressão sertaneja (que engloba serras e campos de inselbergs), planícies fluviais, planícies flúvio-marinhas e campos de dunas (móveis ou fixas) (Souza, 2000).

A classificação do clima é Aw (clima tropical de savana, também conhecido por clima savânico, clima tropical com estação seca, clima tropical de estações úmida e seca ou ainda clima tropical semi-úmido) de acordo com os critérios de Köppen e Geiger. O período chuvoso ocorre entre os meses de fevereiro a maio. A temperatura média anual varia entre $26^{\circ} \mathrm{C}$ a $28^{\circ} \mathrm{C}$ e a precipitação pluviométrica média anual é de 1.243,2 mm (FUNCEME, 2019).

Caucaia situa-se na bacia hidrográfica metropolitana de Fortaleza e seus rios de maior porte são o Ceará, Cauipe e Anil. Lagoas e açudes podem ser encontrados na região, com destaque para os açudes Sítios Novo e Cauipe, Fig. 2.

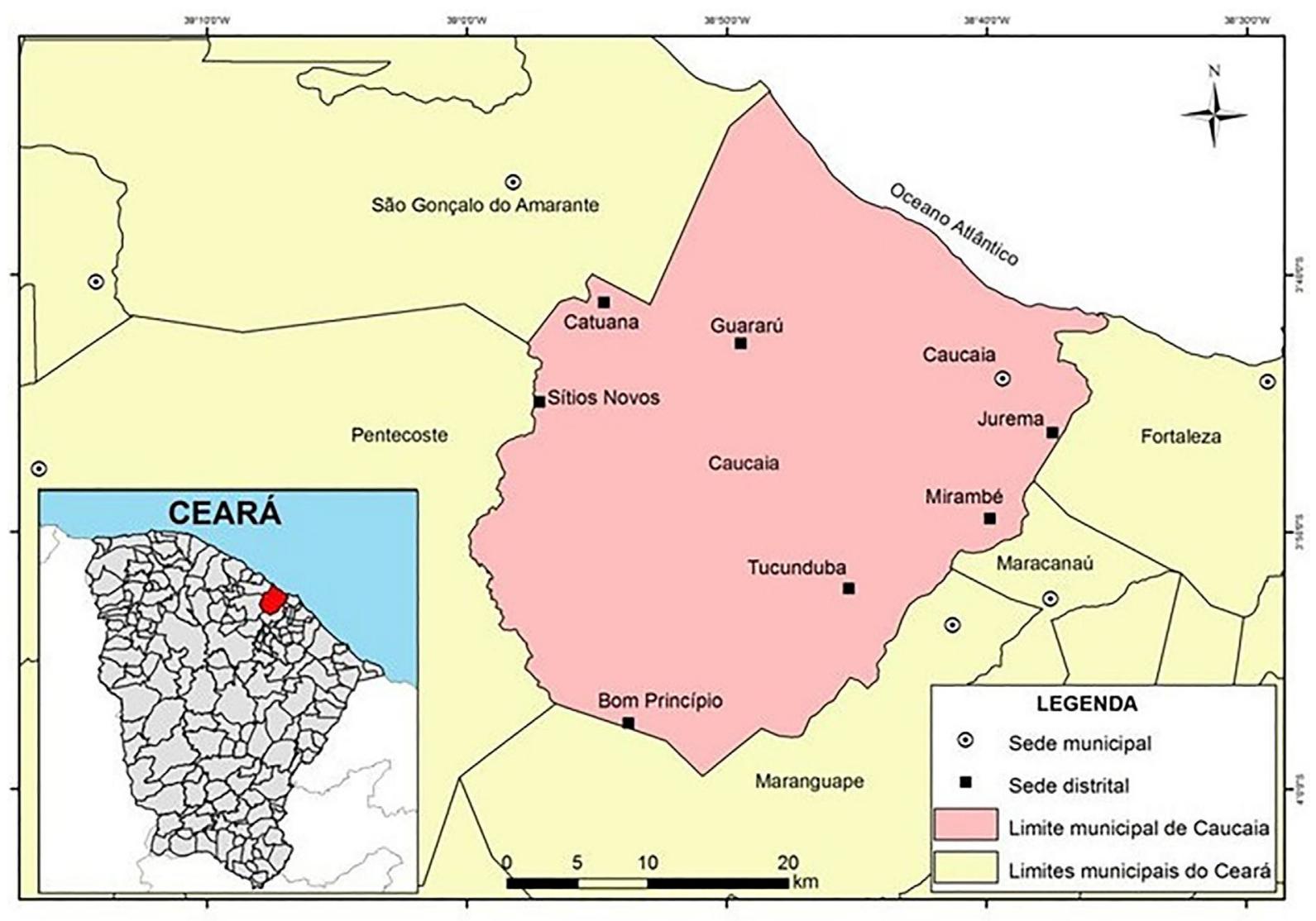

Figura 1 - Localização da Área de Estudo. 


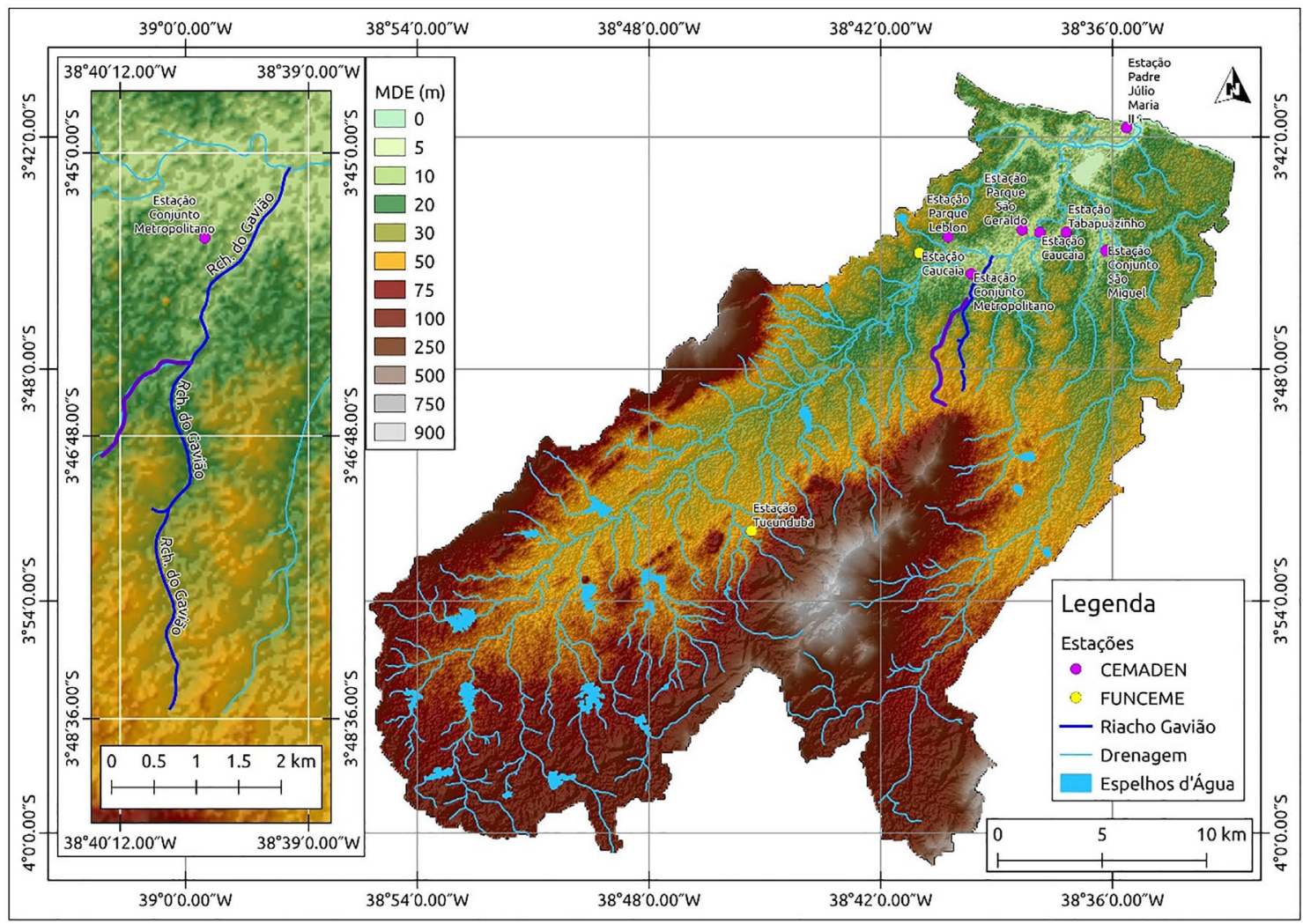

Figura 2 - Mapa Hidrográfico de Caucaia, com detalhes do Riacho Gavião popularmente conhecido como Rio Picuí.

De acordo com a divisão de classificação, do Serviço Geológico do Brasil e Companhia de Pesquisas de Recursos Minerais - CPRM, o município de Caucaia possui 17 áreas de risco que estão agrupadas nos nove setores. Estas são áreas consideradas impróprias ao assentamento humano por estarem sujeitas a riscos naturais (chuvas, ventos e etc.) ou decorrentes da ação do homem.

A área denominada de região 4 (Conjunto Metropolitano), é o objeto deste estudo. Esta área, assim como as demais, tem apresentado índices de vulnerabilidade crescentes, o que vem causando sérios danos à população e a seus bens, principalmente no período de chuvas. Esses danos tendem a se perpetuar, a não ser que atitudes concretas sejam tomadas no sentido contrário. O Slapvoip foi desenvolvido visando contribuir para a mitigação dos problemas citados acima. Tendo como base o software Linux Ubuntu, o Slapvoip envia aos responsáveis e aos interessados, mensagens de alerta relativas às possibilidades de ocorrência destas vulnerabilidades.

Foram obtidos dados de precipitação e registros das ocorrências de cheias disponíveis nos arquivos das instituições responsáveis e a partir daí, uma tabela que possibilitou a comparação entre as variáveis chuva e intensidade de cheia, foi elaborada. A ocorrência de determinada intensidade de cheia pode então ser estimada a partir da ocorrência de um determinado volume de precipitação, sendo classificadas em: não existentes, fracas, moderadas e fortes. Os dados de precipitação usados no desenvolvimento deste trabalho foram coletados pelo CEMADEN, na Cidade de Caucaia, conforme a Tabela 1. Os pluviômetros utilizados são todos do mesmo tipo, sendo o do Conjunto Metropolitano, objeto deste estudo, apresentado na Fig. 3 como exemplo.

Dados coletados pela FUNCEME também foram analisados, para os meses de janeiro a abril de 2019. Naquele período as chuvas registradas no Estado do Ceará foram intensas, tendo alcançado valores superiores aos de anos anteriores. Na capital, os registros referentes aos três primeiros meses do ano atingiram valores de chuva de

Tabela 1 - Localização dos Pluviômetros do CEMADEN na Cidade de Caucaia.

\begin{tabular}{llllll}
\hline Local & & UF & Bairro & Longitude & Latitude \\
\hline Caucaia & 230370901 a & Ce & Tabapuãnzinho & $-38,62$ & $-3,741$ \\
Caucaia & 230370902 a & Ce & Parque São Geraldo & $-38,639$ & $-3,74$ \\
Caucaia & $230370903 a$ & Ce & Conjunto Metropoli- & $-38,661$ & $-3,759$ \\
& & & tano & & \\
Caucaia & $230370903 h$ & Ce & Caucaia & $-38,6314$ & $-3,7411$ \\
Caucaia & $230370904 a$ & Ce & Parque Leblon & $-38,671$ & $-3,743$ \\
Caucaia & $230370905 a$ & Ce & Padre Júlio Maria II & $-38,594$ & $-3,696$ \\
Caucaia & $230370906 a$ & Ce & Conjunto São & $-38,603$ & $-3,749$ \\
& & & Miguel & & \\
\hline
\end{tabular}

Fonte: CEMADEN, 2019. 


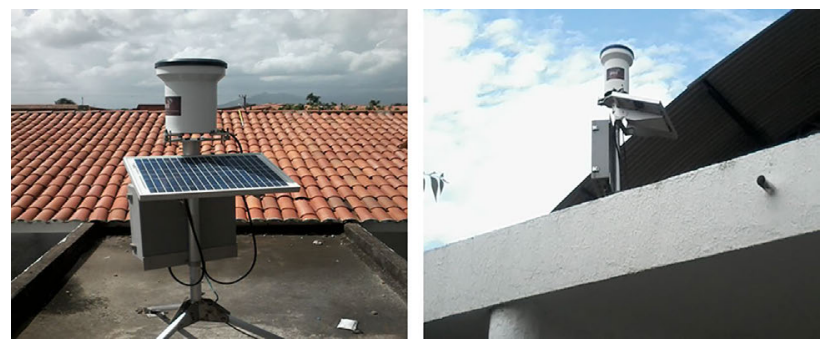

Figura 3 - Vista da Estação - Conjunto Metropolitano

mais que o dobro dos valores esperados para a média histórica de chuvas. Em abril, choveu mais de $60 \%$ do esperado para o mês inteiro em apenas seis dias, conforme a Fig. 4.

\subsection{Desenvolvimento e programação do Sistema Slapvoip}

A pesquisa realizada para fundamentar este trabalho, não encontrou qualquer sistema que fizesse uso da telefonia IP/Voip (Voz sobre protocolo de internet), com envio de SMS (Serviço de Mensagens Curtas). Considerando que o sistema Voip utiliza o protocolo SIP (Protocolo de Iniciação e Sessão), que é um protocolo inteiramente voltado à serviços oferecendo baixo custo de implementação, recursos para a melhoria da mobilidade e produtividade de usuários, como da Defesa Civil, esta foi a opção escolhida. Isto possibilitou a classificação dos patamares de cores, o envio de e-mails, à geração de futuros relatórios através de seu banco de dados, e a recepção automática das ligações PSTN (Rede Telefônica Pública Comutada), mesmo sem a necessidade de estar conectada à internet. Estas caracte- rísticas de funcionalidade são consideradas um diferencial, quando comparado com aqueles existentes no mercado.

Devido sua simplicidade, essa tecnologia pode ser executada em hardwares de pouca funcionalidade e baixa velocidade de processamento, incluindo aqueles considerados obsoletos e normalmente descartados, o que elimina qualquer problema de compatibilidade de hardware. O "cloud computing", conhecido por "nuvem", que permite a diminuição dos custos do projeto, também foi usado. Desta forma, a tecnologia VOIP foi alocada no servidor de nuvem da empresa Digital Ocean, contratada para este objetivo. Um esquema é apresentado na Fig. 5.

$\mathrm{O}$ projeto foi dividido em duas fases. $\mathrm{Na}$ primeira o sistema foi programado para identificar as mensagens de alarme, a partir de qualquer chuva precipitada. Este foi desenvolvido utilizando-se duas telas de cores. Uma de cor cinza, onde estava escrito "sem alarmes", e a outra de cor laranja, onde está estava escrito "Alarmes". Aqui, também, foi especificado que os envios das mensagens de SMS e chamadas telefônicas, seriam enviadas com qualquer precipitação de chuvas.

$\mathrm{Na}$ segunda fase, os dados de chuva coletados pelos pluviômetros do CEMADEN, e os registros de cheias dos arquivos da Defesa Civil da Cidade de Caucaia, foram obtidos e confrontados. A Tabela 2 apresenta os valores de precipitação ocorridos nas várias estações pluviométricas localizadas na circunvizinhança da região em estudo, nas datas concomitantes, com os eventos registrados pela Defesa Civil, Tabela 3. Desta forma, iniciou-se o desenvolvimento do sistema através das programações do servidor PABX/ Asterisk (Central Automática de Telefonia Convencional - Asterisk). A disponibilidade da série de dados de precipitação coletada através do pluviômetro da

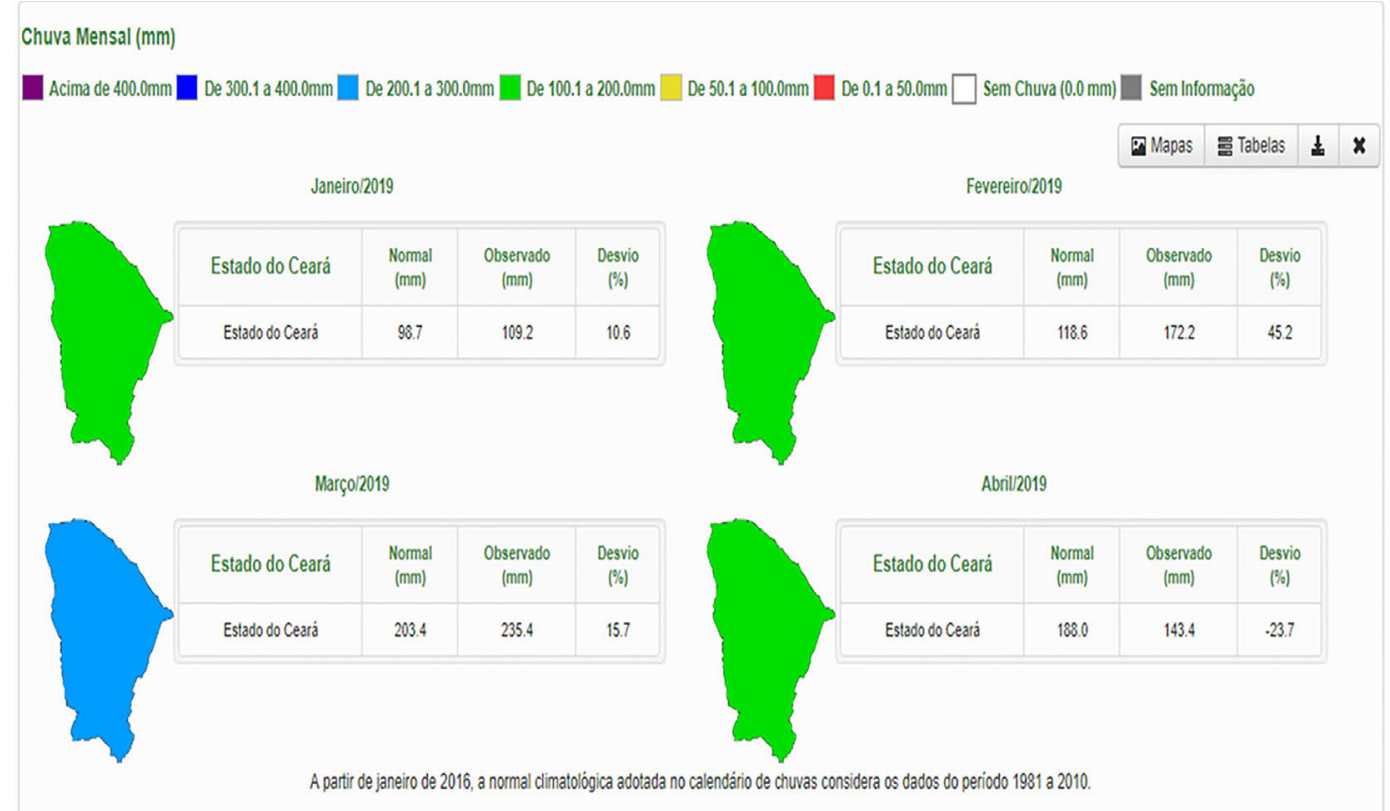

Figura 4 - Registro de Chuvas de janeiro a abril de 2019 no Estado do CE. 


\section{Componentes}

\section{Cenário típico de uma rede corporativa com serviços VoIP}

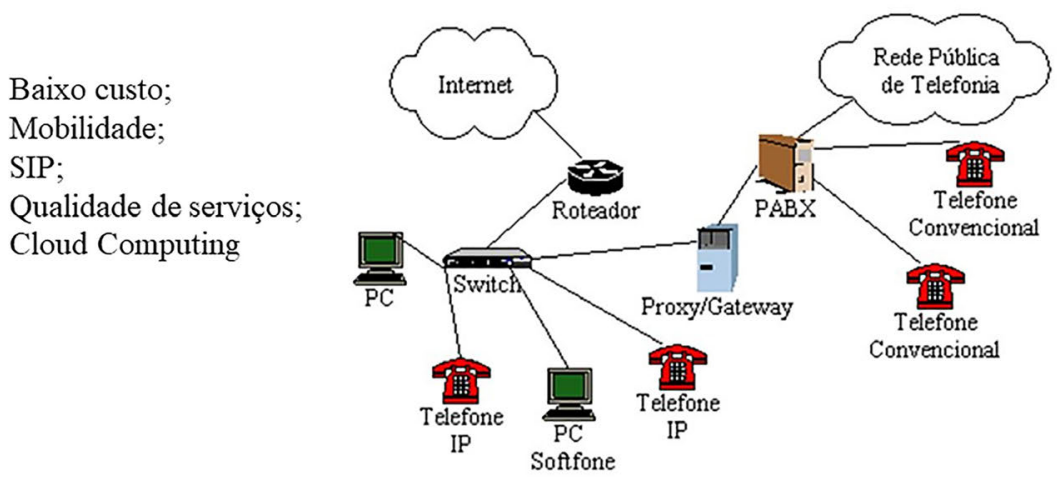

Fonte : Netwave Telecom -Voip

Figura 5 - Esquema de funcionamento do Sistema Slapvoip.

Tabela 2 - Datas dos Registros com precipitações dos Pluviômetros do CEMADEN.

\begin{tabular}{lcccccccc}
\hline Data & $\begin{array}{c}\text { Conjunto metropo- } \\
\text { litano }\end{array}$ & $\begin{array}{c}\text { Parque } \\
\text { Leblon }\end{array}$ & $\begin{array}{c}\text { Conjunto São } \\
\text { Geraldo }\end{array}$ & $\begin{array}{c}\text { Estação } \\
\text { Caucaia }\end{array}$ & Tabapuã & $\begin{array}{c}\text { Conjunto São } \\
\text { Miguel }\end{array}$ & $\begin{array}{c}\text { Parque Júlio } \\
\text { Maria }\end{array}$ & $\begin{array}{c}\text { Referência Estação Cau- } \\
\text { caia Funceme }\end{array}$ \\
\hline Abril/2015 & 97,59 & 91,04 & 263,64 & 452,27 & 425,94 & 117,62 & 113,26 & 424,2 \\
Março/2017 & 13,48 & 404,89 & 423,91 & 445,4 & 450,23 & 460,92 & 491,84 & 487,8 \\
Abril/2017 & 1,2 & 391,13 & 257,96 & 312,6 & 320,78 & 325,7 & 329,28 & 487,8 \\
Maio/2017 & 0 & 0 & 126,87 & 142,2 & 140,51 & 133,16 & 135,97 & 155.5 \\
Fevereiro/ & 311,86 & 0 & 310,82 & 325,6 & 311,92 & 281,03 & 312,97 & 281,2 \\
2018 & & & & & & & & 295,01 \\
Março/2018 & 200,76 & 0 & 196,56 & 159,2 & 208,14 & 203,14 & 295 & 170,7 \\
Abril/2018 & 284,97 & 0 & 253,5 & 18,4 & 269,82 & 247,6 & 342,45 & 236,6 \\
\hline
\end{tabular}

Fonte: Defesa Civil, 2019.

Estação Caucaia da FUNCEME, possibilitou uma comparação com os dados do CEMADEN, o que proporcionou uma maior confiabilidade nos resultados a serem apresentados. Esta comparação mostrou que, das estações do CEMADEN, a do Parque São Geraldo é a que apresenta a serie mais completa $\mathrm{e}$, consequentemente, foi à escolhida como referência para este estudo.

\section{Resultados e Discussão}

Com os resultados das análises acima e com registros encontrados, os níveis das possíveis cheias foram classificados em quatro categorias que são: Ausência de Cheia, Cheia Moderada, Cheia Forte, e Cheia Muito Forte. Essas categorias correspondem respectivamente às cores de tela cinza, amarelo, laranja e vermelho. Este sistema de cores é relativo e depende do grau de dificuldade encontrado pelo corpo técnico da Defesa Civil, em realizar suas tarefas de auxílio às populações afetadas.
A intensidade da cheia corrente é apresentada como função dos resultados da classificação dos limiares de precipitação que são apresentados na Tabela 4.

Uma vez definidos os limiares de cores e precipitação, o programa é compilado. Após a compilação, os registros dos usuários, Fig. 6, podem ser feitos. Para logar no sistema, através do link Slapvoip.cf, o usuário é solicitado a preencher um pequeno formulário com seus dados.

Feito isto, estará capacitado a registrar que está ciente do recebimento da mensagem lhe enviada via SMS, e visualizar através de uma das cores descritas anteriormente, qual a intensidade desta possível cheia, Fig. 7.

Uma vez que o usuário já esteja cadastrado e logado no sistema, caso ocorra um evento significativo, receberá um SMS. Neste SMS ele poderá tomar ciência dos detalhes desta ocorrência, tais como a quantidade de chuva precipitada e a intensidade da provável cheia associada, Fig. 8.

Durante o primeiro semestre de 2019, observou-se a ocorrência de incidentes na região de Caucaia, como por exemplo, o do dia 24 de fevereiro de 2019. Neste dia a 
Tabela 3 - Datas dos registros das ocorrências registradas pela Defesa Civil de Caucaia.

\begin{tabular}{|c|c|c|}
\hline $\begin{array}{l}\text { Dados dos registros } \\
\text { /ocorrências }\end{array}$ & Bairro & $\begin{array}{l}\text { Descrição dos registros de } \\
\text { ocorrências }\end{array}$ \\
\hline $10 / 04 / 2015$ & Itambé & Alagamento de Ruas e Casas \\
\hline 09/03/2017 & Jandaiguaba & $\begin{array}{c}\text { Alagamento - canal obstruído } \\
\text { por lixo }\end{array}$ \\
\hline 09/03/2017 & Grilo & Casa com alagamento \\
\hline 09/03/2017 & Arianópolis & $\begin{array}{c}\text { Alagamento - canal obstruído } \\
\text { por lixo }\end{array}$ \\
\hline 09/03/2017 & Arianópolis & Alagamento \\
\hline 09/03/2017 & $\begin{array}{l}\text { Parque das } \\
\text { Nações }\end{array}$ & Alagamento \\
\hline 09/03/2017 & Tapuan & Alagamento em Área de Risco \\
\hline $10 / 03 / 2017$ & $\begin{array}{l}\text { Parque Sole- } \\
\text { dade }\end{array}$ & Casa com alagamento \\
\hline $27 / 03 / 2017$ & Parque Leblon & Alagamento na avenida \\
\hline $18 / 04 / 2017$ & Jandaiguaba & Alagamento \\
\hline $18 / 04 / 2017$ & Santa Rosa & Alagamento \\
\hline $24 / 04 / 2017$ & Tabuba & $\begin{array}{l}\text { Alagamento em Residência, } \\
\text { bueiro entupido }\end{array}$ \\
\hline 08/05/2017 & Icaraí & $\begin{array}{l}\text { Alagamento - avarias nas } \\
\text { estradas vários buracos }\end{array}$ \\
\hline $12 / 02 / 2018$ & Soledade & Alagamento de Rua \\
\hline $16 / 02 / 2018$ & Jandaiguaba & Alagamento Recorrente \\
\hline $13 / 03 / 2018$ & $\begin{array}{l}\text { sem identifica- } \\
\text { ção }\end{array}$ & Sem identificação \\
\hline $22 / 03 / 2018$ & $\begin{array}{l}\text { Parque. Júlio } \\
\quad \text { Maria }\end{array}$ & $\begin{array}{l}\text { Alagamento om risco emi- } \\
\text { nente de desabamento }\end{array}$ \\
\hline $18 / 04 / 2018$ & Santa Rosa & Alagamento \\
\hline
\end{tabular}

Fonte: Defesa Civil, 2019.
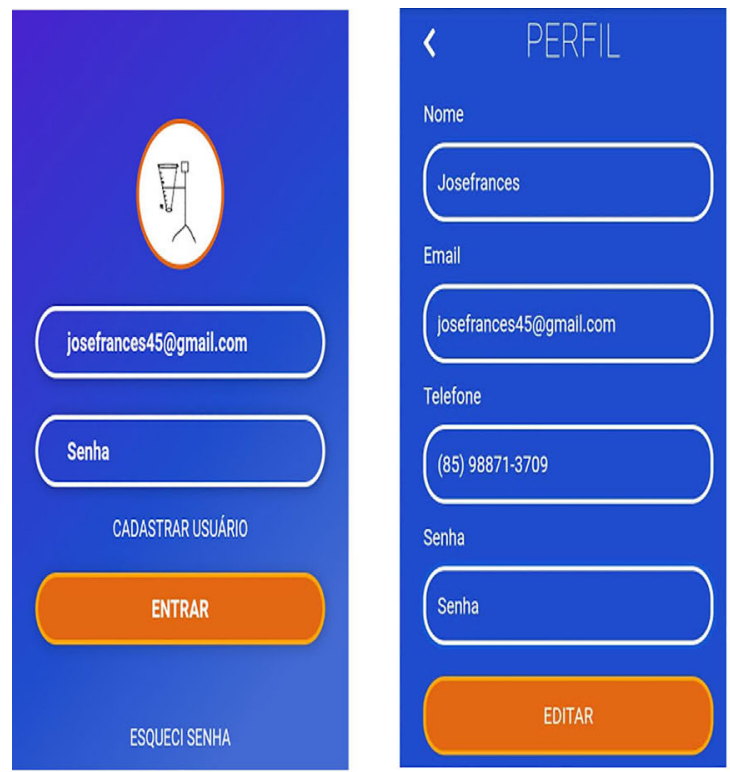

Tabela 4 - Cores dos Alertas e limiares dos índices de envio SMS.

\begin{tabular}{ccc}
\hline Cores & Modalidade & $\mathrm{mm}$ \\
\hline & sem cheias & 0 a 1,1 \\
& cheia moderada & 1,2 a 15 \\
& cheia forte & 15,1 a 30 \\
& cheia muito forte & 30,1 em diante \\
\hline
\end{tabular}

FUNCEME registrou uma precipitação com aproximadamente $109 \mathrm{~mm}$ de intensidade. Além dos registros feitos pela imprensa escrita, falada e televisada, a Defesa Civil de Caucaia também registrou vários pontos com alagamentos, como o do Conjunto Metropolitano. A reportagem do Jornal o Povo daquele dia (Jornal local), apresentou incidentes ocasionados pelas chuvas na região com o seguinte título: "cerca de 50 famílias da Comunidade dos Tapebas, tiveram as casas invadidas pela água devido à cheia do Rio Ceará, que a forte chuva provocou alta do rio e a inundação de residências e ruas", conforme a Fig. 9.

No dia 6 de março do mesmo ano, em outro evento na região metropolitana, a cidade de Fortaleza teve suas ruas inundadas por uma chuva que acumulou $30,2 \mathrm{~mm}$. No dia seguinte, o Diário do Nordeste apresentou valores de alguns dos registros de chuvas feitos pela FUNCEME, tais como Caucaia (Posto Caucaia) - 80,6 mm; Amontada (Posto Icaraí de Amontada) - $77 \mathrm{~mm}$; Caucaia (Posto Sítios Novos) - 75 mm; São Gonçalo do Amarante (Posto Croatá): 74 mm; São Gonçalo do Amarante (Posto Sede) $72 \mathrm{~mm}$. Precipitações acima da média como essas, geralmente causam grandes transtornos nessas áreas, de acordo com relatos do CEMADEN. Um exemplo do funcionamento pôde ser visto através da reportagem do jornal

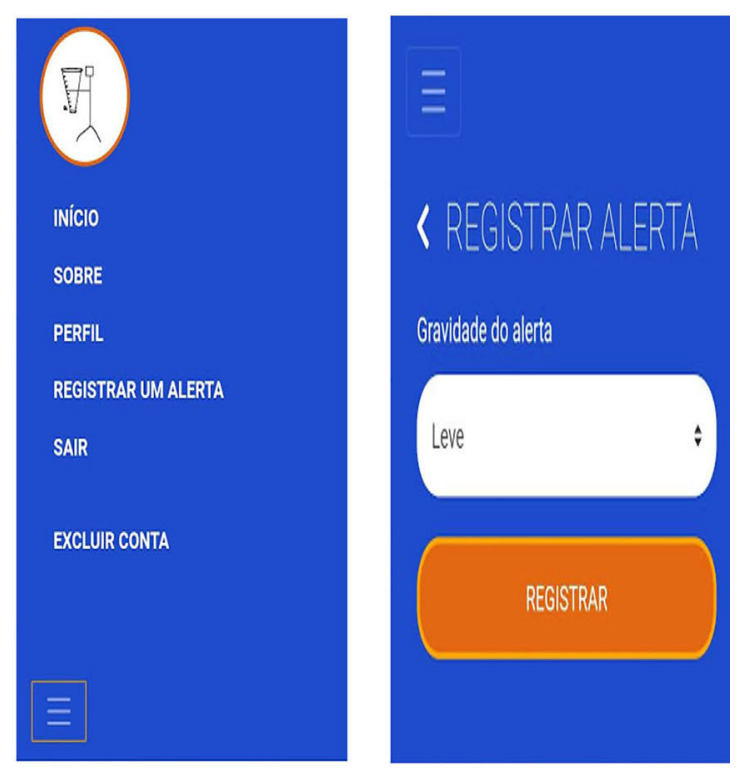

Figura 6 - Telas de cadastramento dos usuários e Registro dos Alerta. 


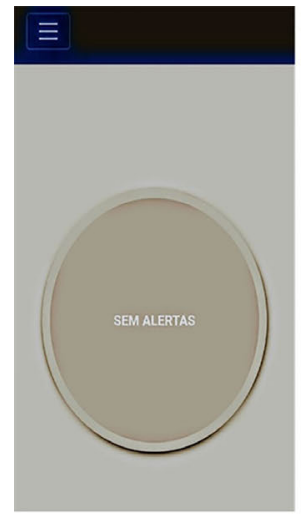

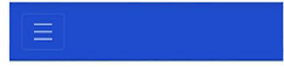
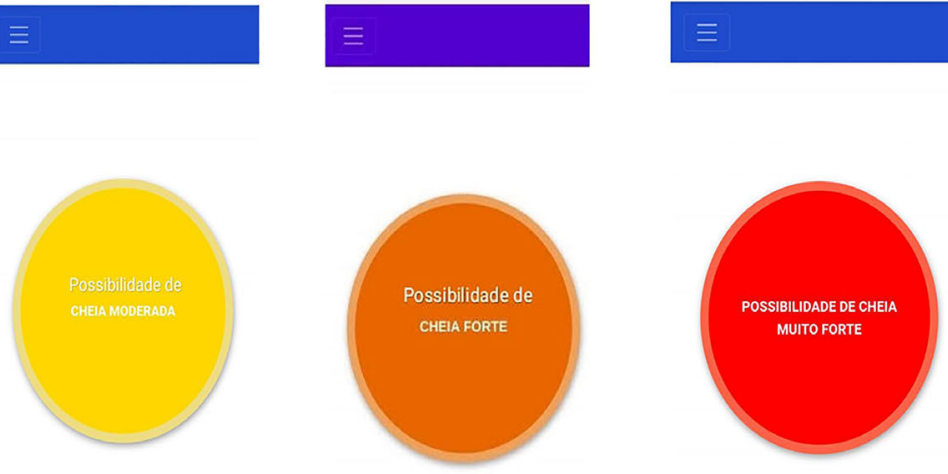

Figura 7 - Telas após o login no Slapvoip.cf, ilustrando as possibilidades das cheias.

Metrópole News de Caucaia, Fig. 10. Neste dia o jornal apresentou uma cheia, que inundou vários bairros daquela cidade. Essa cheia não foi registrada por parte da Defesa Civil, mas o Slapvoip, em funcionamento no momento, registrou as informações pertinentes e enviou as mensagens SMS.

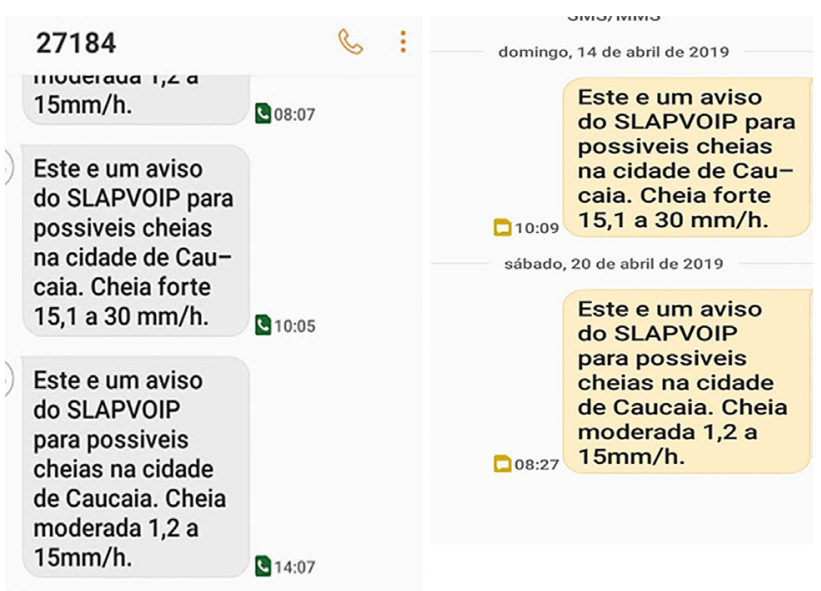

Figura 8 - Resultados dos envios de SMS.

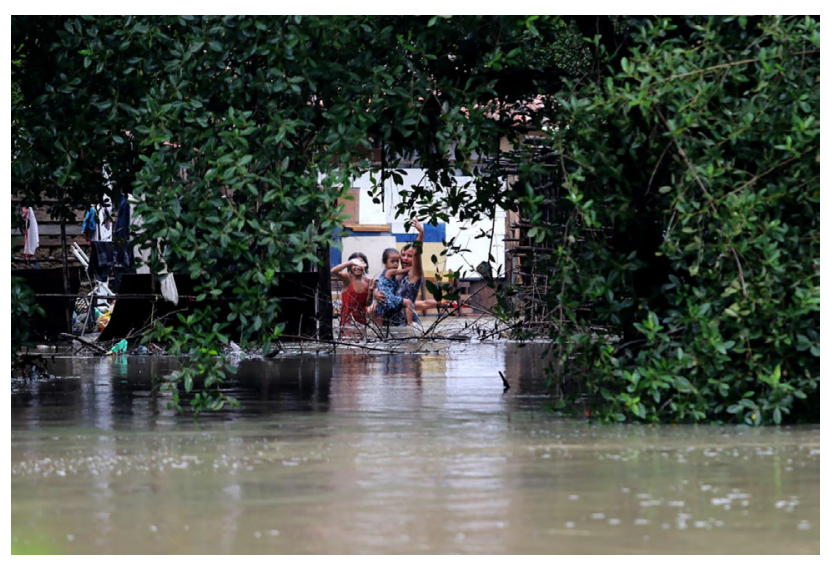

Figura 9 - Chuva ocorrida no dia 24 de fevereiro de 2019, na cidade de Caucaia.
Visando continuar os testes, o sistema permaneceu ligado no mês de abril. Este foi um mês onde a quantidade de precipitação naquela região foi acima da média $(60 \%)$, como citado anteriormente. Outro caso, também registrado no dia 20-04-2019 pela reportagem do jornal o povo, informou que entre a noite de sexta-feira do dia 19 e a manhã do dia 20 de abril, a região metropolitana registrou $111.4 \mathrm{~mm}$ de chuva. Para esta precipitação, o Slapvoip emitiu, às $8 \mathrm{~h} 27$ do mesmo dia, um SMS com os incrementos e os decrementos relativos a essa chuva, avisando sobre as possíveis cheias em Caucaia.

É importante observar que todos os registros enviados via SMS, inclusive o registro de visualização por parte do usuário, é automaticamente incluído no Banco de dados

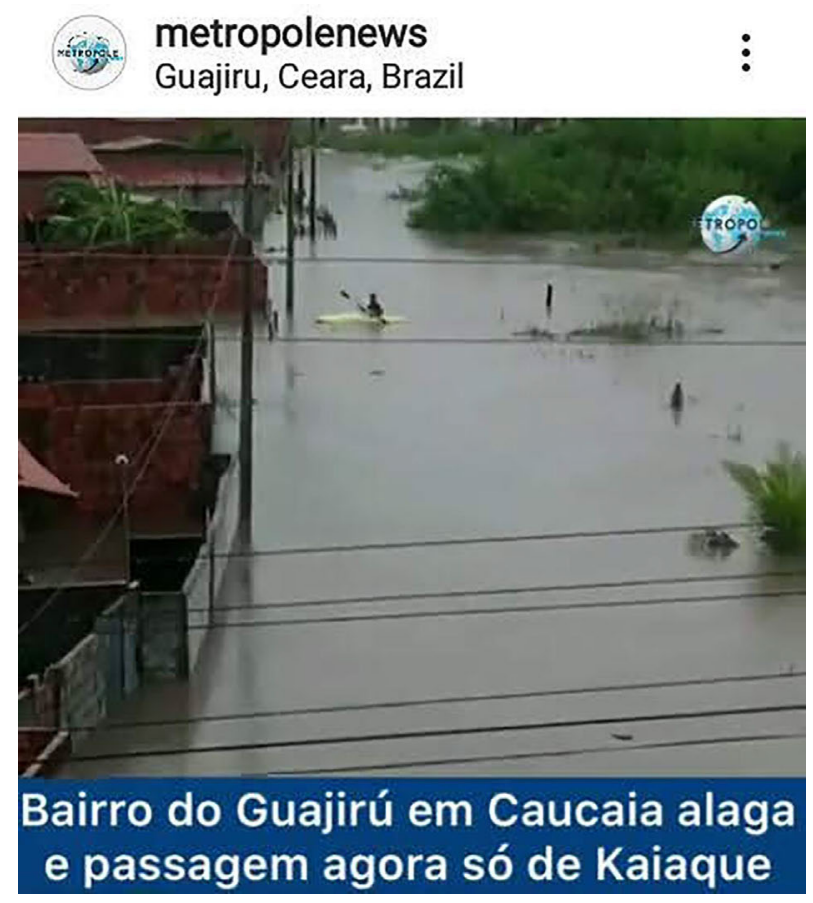

Figura 10 - Reportagem da Metrópole News com cheias de Caucaia em 14 de abril 2019. 
do Slapvoip, e ficam disponíveis para consulta no endereço IP http://204.48.18.215/alertas/getall.

\section{Conclusões}

A utilização da tecnologia Voip pôde ser desenvolvida ao longo dessa pesquisa, com a vantagem de ser de resposta rápida e de baixo custo, o que reflete na economia com operadoras de telefonia. A simplicidade do Slapvoip permite a utilização de sistemas computacionais tão simples quanto aqueles que atualmente poderiam até ser considerados como obsoletos.

Tendo sido classificadas as informações em um padrão de cores, conforme os índices pluviométricos estabelecidos, o sistema fez o envio, dentro dos limiares sugeridos pelo estudo, gerando chamadas telefônicas que foram registradas no banco de dados SQL do Slapvoip, para criação de um banco de dados eficaz para possíveis estudos futuros.

Sendo usado adequadamente, o sistema constitui-se de uma ferramenta capaz de ajudar os governos, com suas Defesas Civis, a obter mais eficiência nos seus planos e ações sócios educativas, junto à população que vive em áreas de vulnerabilidade e produzindo informações úteis para a população que vive em áreas de risco, sofrendo com cheias e inundações, possibilitando a aceleração nas ações dos organismos governamentais responsáveis por sua mitigação.

\section{Agradecimentos}

Agradecemos ao INPE, na sua unidade Eusébio, pelo acolhimento do projeto e disponibilização de recursos computacionais; à FUNCEME pelo acolhimento do projeto e disponibilização dos dados; ao CEMADEM por possuir uma política de disponibilização de dados na internet; e ao programa de pós-graduação da UECE pelos ensinamentos recebidos na consecução do grau de mestre do primeiro autor.

\section{Referências}

ALEXANDER, DE. Natural hazards on an unquiet earth. In: MATTHEWS, J.A.; HERBERT, D.T. Unifying Geography: Common Heritage, Shared Future? New York: Routledge, chap. 12, p. 266-282, 2004.

AMARAL, R.; GUTJAHR, M.R. Desastres Naturais. São Paulo: IG/SMA, 2011. Disponível em http://www.ciaden. com.br/docs/gerais/CEA_DESASTRES.pdf, acesso em 04 dez. 2013.

CASTRO Antônio Luiz Coimbra de; CALHEIROS, Lélio Bringel. Manual de Medicina de Desastres. 2 ed. Brasília: Ministério da integração, 2007.

CENTRO NACIONAL DE MONITORAMENTO E ALERTAS DE DESASTRES NATURAIS. Alertas de Desastres Na- turais. Fortaleza: CNMADN, 2019. Disponível em http:// www.cemaden.gov.br/, acesso em 18 maio 2019.

Metrópole News. Cheias de Caucaia em 16 de abril. Metrópole News, Fortaleza, 16 abr. 2019. Disponível em http://www. metropolenewscaucaia.com.br/, acesso 27 jun. 2019.

COMPANHIA DE PESQUISA DE RECURSOS MINERAIS. Ação Emergencial para Reconhecimento de Áreas de Alto e Muito Alto Risco a Movimentos de Massa e Enchentes: Caucaia, Ceará. Caucaia: CPRM, 2012. Disponivel em http://rigeo.cprm.gov.br/jspui/handle/doc/ 18944, acesso em 17 maio 2019.

CAUCAIA. Defesa Civil de Caucaia. Caucaia: Prefeitura de Caucaia, 2019. Disponível em http://www.defesacivil.ce. gov.br/index.php?option=com_content\&view $=$ arti cle $\&$ id $=259$ : caucaia\&catid=14:lista-de-noticias \&Ite mid=81, acesso em 25 maio 2019.

FUNDAÇÃO CEARENSE DE METEOROLOGIA E RECURSOS HÍDRICOS. Recursos Hídricos. Fortaleza: FUNCEME, 2019. Disponível em http://www.funceme.br/, acesso em 18 maio 2019.

INSTITUTO BRASILEIRO DE GEOGRAFIA E ESTATÍSTICA. Censo Populacional 2010. Rio de Janeiro: IBGE, 2010. Disponível em http://www.ibge.gov.br/, acesso em 18 out. 2018.

KÖPPEN, W.; GEIGER, R. Klimate der Erde. Gotha: Verlag Justus Perthes, 1928.

MARANDOLA Jr., E.; HOGAN, D.J. Natural hazards: o estudo natural hazards: $O$ estudo geográfico dos riscos e perigos. Ambient. Soc., v. 7, n. 2, p. 95-110, 2004.

RELATÓRIO ANUAL BANCO MUDIAL. A Natureza do Espaço: Técnica e Tempo, Razão e Emoção. São Paulo: Edusp, 2012. 384 p.

SOUZA, M.J.N. Bases Naturais e Esboço do Zoneamento Geoambiental do Estado do Ceará. Fortaleza: FUNECE, 2000.

SOUZA, Marcos José Nogueira de. Contribuição ao estudo das unidades morfoestruturais do Estado do Ceará. Revista de Geologia, Fortaleza, n. 1, v. 1, 1988.

SOUZA, M.J.N.; BRANDÃO, R.L.; CAVALCANTE, I.N. Diagnóstico Geoambiental e os Principais Problemas de Ocupação do Meio Físico da RMF. Fortaleza: CPRM, 1995. 120p.

UNIVERSIDADE FEDERAL DE SANTA CATARINA. Atlas Brasileiro de Desastres Naturais 1991 a 2012. 2. ed. Florianópolis: CEPED, 2013.

TOMINAGA, L.K.; AMARAL, J.S.R. Desastres Naturais: Conhecer Para Prevenir. São Paulo: Instituto Geológico, 2009.

Diário do Nordeste. Veja a destruição causada pela chuva no mês de março no Ceará. O Diário do Nordeste, Fortaleza, 1 abr. 2019. Disponível em https://diariodonordeste.verdes mares.com.br/editorias/regiao/online/veja-a-destruicao-cau sada-pela-chuva-no-mes-de-marco-no-ceara-1.2081001, acesso em 8 jun. 2019.

License information: This is an open-access article distributed under the terms of the Creative Commons Attribution License (type CC-BY), which permits unrestricted use, distribution and reproduction in any medium, provided the original article is properly cited. 